\title{
A viagem em busca da identidade perdida no passado esplendoroso e a dessacralização do mito do descobridor português n'A jangada de pedra, de José Saramago
}

\author{
Adauto Locatelli Taufer*
}

\begin{abstract}
Resumo: Este ensaio representa a síntese de uma comunicação apresentada na disciplina Seminário de Autor: José Saramago do Curso de Pós-Graduação do Curso de Letras (PPGLET) da UFRGS. Para a realização deste estudo, a fonte de inspiração foi a predestinação do povo português às navegações. $\mathrm{O}$ recorte apresentado focaliza dois dos principais aspectos da história e cultura portuguesas, desenvolvidas por Saramago no romance A Jangada de Pedra: a viagem em busca da identidade perdida no passado esplendoroso e a dessacralização do mito do descobridor português. N'A Jangada de Pedra, a Península Ibérica é desmembrada do Continente Europeu e vai navegando pelo oceano Atlântico, numa viagem à deriva, cuja imagem utópica simboliza a procura da identidade perdida de Portugal através do desprendimento alegórico da Península Ibérica do Continente Europeu.
\end{abstract}

Palavras-chave: identidade; mito; passado glorioso; viagem.

\begin{abstract}
This essay represents the synthesis of a communication presented in the Seminary of Author: Jose Saramago, a course in the Post-graduation Program, Language School (PPGLET) at the Federal University of Rio Grande do Sul (UFRGS). What motivated this study was the predestination of the Portuguese people to navigations. Our approach focuses on two of the main aspects of Portuguese history and culture, developed by Saramago in the novel The stone raft: the journey in search of the lost identity of the glorious past and the deconstruction of Portuguese discoverer myth. In the The stone raft the Iberian Peninsula is separated from the European Continent and goes on sailing and drifting on the Atlantic Ocean; its utopian image symbolizes the search for the lost identity of Portugal through the symbolic un-attachment of the Iberian Peninsula from the European Continent
\end{abstract}

Keywords: identity; myth; glorious past; journey.

... que somos nós, por ter sido, não nos parece ser dissolvido ou realmente ameaçado por perigo algum vindo do exterior, improvável federação hispânica ou provável, no futuro, confederação européia. Em qualquer entidade transnacional que nos pensemos, figuraremos sempre com uma identidade que é menos a da nossa vida e capacidade colectiva

\footnotetext{
“Adauto Locatelli Taufer é aluno do Programa de Pós-Graduação em Letras da UFRGS, bolsista da CAPES.
} 
própria, do que essa de actor histórico privilegiado da aventura mundial européia. (Eduardo Lourenço) ${ }^{1}$

Nós pensamos saber quem somos por ter sido largamente quem fomos e pensamos igualmente que nada ameaça a coesão e a consistência da realidade nacional que constituímos. (Eduardo Lourenço) ${ }^{2}$

Embora José Saramago rejeite, é comum ver seu nome relacionado aos escritores neorealistas - corrente que foi fundamentada por ideais e propostas esquerdistas, defensora de uma sociedade mais justa e igualitária - considerados os porta-vozes dos indivíduos pertencentes às classes sociais mais carentes. Ao rótulo de escritor neo-realista Saramago reage - numa entrevista concedida a Cremilda Araújo Medina (1983), em Viagem à Literatura Portuguesa Contemporânea - deixando evidente que as preocupações do escritor ultrapassam os questionamentos político-partidários e ideológicos:

\begin{abstract}
Não gosto de favas nem de demagogia. Os condicionamentos do neo-realismo são uma falsa questão. Mesmo quando escrevi textos ficcionais com maior vinculação com fatos políticos, como A noite, não passei pela tentação da demagogia e nem a crítica de extrema-direita pode apontar ou ousar falar de qualquer forma de demagogia. Escrevo os livros que entendo. A competição do escritor é pessoal e não partidária. (MEDINA, 1983, p.267)
\end{abstract}

Não restam dúvidas de que José Saramago é tido como um dos grandes nomes da prosa portuguesa contemporânea. Sua inventividade, aliás, pode ser percebida na medida em que se avança na leitura de sua obra. Em seu romance A Jangada de Pedra, o leitor é convidado a embarcar numa viagem em que, mais uma vez, a genialidade desse escritor português é reafirmada, seja pela tentativa de resgatar a identidade perdida no passado esplendoroso, seja pela dessacralização do mito do descobridor português.

O recorte apresentado é o resultado obtido a partir de dois significativos aspectos da cultura portuguesa: a nevrálgica questão envolvendo a sua identidade (ser português no passado glorioso e no presente globalizado) e a sua predestinação às conquistas marítimas, revivida, ainda que às avessas e de modo alegórico, nesse romance saramaguiano. Especificamente com relação a esta última perspectiva é inevitável o contraponto com a obra Os Lusíadas, de Luís Vaz de Camões.

\footnotetext{
${ }^{1}$ LOURENÇO, Eduardo. O labirinto da saudade: psicanálise mítica do destino português. 5.ed. Lisboa: Dom Quixote, 1992.

${ }^{2}$ LOURENÇO, Eduardo. Nós e a Europa ou as duas razões. 4.ed. Lisboa: Imprensa Nacional/Casa da Moeda, 1994.
} 


\section{Ser português, eis a questão: a identidade portuguesa}

Quem sou eu? Essa parece ser uma das grandes indagações metafísicas inerentes ao ser humano. Para Portugal, no entanto, essa parece ser, há muito tempo, a pergunta que não quer calar.

Seguindo a trilha de Eduardo Lourenço, é válida a reflexão de que a literatura tem elaborado, de Camões a Saramago, um árduo esforço de interpretar Portugal, buscando - com isso - possíveis causas aos traumas sofridos pelo país ao longo de mais de seis séculos de história. Por isso, a problemática discussão entorno da identidade portuguesa tem-se caracterizado como um dos principais eixos condutores, tanto para a história do povo português quanto para a história da sua literatura.

Para Lourenço (1994), em Nós e a Europa os as Duas Razões, a identidade, de um modo genérico, pode ser assim definida:

Quer para o indivíduo, quer para o grupo, quer para uma nação, a identidade, em sentido óbvio, é um pressuposto [...] para o indivíduo, o grupo, a nação, a questão de identidade é permanente e se confunde com a da sua mera experiência, a qual não é nunca puro dado, adquirido de uma vez por todas, mas o ato de querer e poder permanecer conforme ao ser ou ao projeto de ser aquilo que se é. (LOURENÇO, 1994, p. 9. Destaques do Autor)

A definição de identidade proposta por Eduardo Lourenço reflete diretamente sobre os portugueses. Esses, em geral, parecem querer "permanecer conforme ao ser ou ao projeto de ser aquilo que se é” (LOURENÇO, 1994, p.11), ou melhor, aquilo que se foi. Essa constante rememoração do passado, para Lourenço, exerce uma dupla função sobre os portugueses, uma vez que por um lado, "subtrai-os à consciência deprimida que teria de si sem esse passado" (LOURENÇO, 1994, p.11) por outro, “impede-os de investir na sua vida real, no seu presente" (LOURENÇO, 1994, p.11).

A sombra da identidade passada, desse modo, sobrepõe-se a da presente. O povo português continua rememorando o passado glorioso e, sobretudo, tenta convertê-lo no momento atual, uma vez que não consegue encontrar seu lugar no mundo, sua identidade no tempo de agora. Portugal está preso à identidade passada - fase heróica, em que a nação se consolida, o império se expande, o reino se enriquece - e, por isso, não consegue se inserir na nova ordem mundial, no mundo globalizado, pois este país europeu ainda está preso "à língua, à história, à cultura, à religião e à própria marginalização, no contexto europeu, devido ao seu lado ilha sem o ser" (LOURENÇO, 1994, p.13).

N'A Jangada de Pedra, o complexo de inferioridade de Portugal e a sua sensação de não-pertencimento no mundo europeu são, metaforicamente, as principais causas que 
justificam o desprendimento alegórico da Península Ibérica do continente europeu e motivam a viagem de Portugal e Espanha em busca da identidade perdida. Esse complexo de inferioridade é explicitado dentro da obra quando

os europeus, desde os máximos governantes aos cidadãos comuns, depressa se tinham acostumado, suspeita-se que com um inexpresso sentimento de alívio, à falta das terras extremas ocidentais, e se os novos mapas, rapidamente, postos em circulação para a atualização cultural e popular, ainda causavam à vista um certo desconforto, seria tão-somente por motivos de ordem estética, aquela indefinível impressão de mal-estar que ao tempo há-de ter causado, e ainda hoje nos causa a nós, [...] (SARAMAGO, 1988, p. 151-152).

Sendo assim, esse périplo, a partir dos acontecimentos insólitos ${ }^{3}$ (que envolvem os cinco personagens - dois espanhóis e três portugueses -, que promovem a cisão entre a Península Ibérica do continente europeu), além de retomar um dado histórico em relação aos povos ibéricos, ou seja, a vocação para o mar, reinicia uma tentativa de resgate da identidade portuguesa, seja em nível nacional, seja no plano individual.

Historicamente, o mar é o símbolo-mor das conquistas portuguesas. Portugal tornou-se o grande império graças a ele, uma vez que, durante os séculos XV e XVI, os europeus, principalmente portugueses e espanhóis, lançaram-se nos oceanos Pacífico, Índico e Atlântico com dois objetivos principais: descobrir uma nova rota marítima para as Índias e encontrar e conquistar novas terras para serem anexadas a Portugal e a Espanha.

N'A Jangada de Pedra, o mar é a força que transporta a jangada para a busca de respostas: "no mar estamos, o mar nos leva, para onde o mar nos levará" (SARAMAGO, 1988, p. 136) e para a conseqüente mudança, advinda das respostas, em que a imagem do nascimento da península pode ser lida como a metáfora do resgate da identidade: "viajamos milhares de quilômetros por este mar violentamente aberto [...] a península é uma criança que viajando se formou e agora se revolve no mar para nascer" (SARAMAGO, 1988, p.306).

Em nível nacional, a viagem da península simboliza a ruptura da submissão de Portugal em relação à Europa. Nessa perspectiva, o arquétipo da viagem representa uma tentativa de Portugal fugir da iminente ameaça da mundialização da cultura, devido ao processo de globalização, em virtude da adesão de Portugal à Comunidade Européia (CE). Por isso a península ruma em direção a sua área historicamente natural de conquista e integração: África e América Latina. Desse modo, o encontro da Península Ibérica com a América Central pode ser lido como o encontro de Portugal e Espanha consigo mesmos, uma vez que

\footnotetext{
${ }^{3} \mathrm{O}$ aparecimento de uma fenda nos Pirineus coincide com o instante em que Joana Carda risca o chão com uma vara de negrilho e os cães de Cérbere, antes mudos, começam a ladrar; Joaquim Sassa joga uma pedra enorme ao mar, ela atinge uma distância impossível para suas forças, saltando várias vezes sobre as águas; José Anaiço começa a ser seguido por um enorme bando de estorninhos; Pedro Orce sente que a terra treme sob seus pés; Maria Guavaira desmancha uma meia azul e a quantidade de fio se multiplica, formando uma enorme nuvem.
} 
são as suas línguas, portuguesa e espanhola, que aí ecoam e presentificam o passado esplendoroso das grandes conquistas:

A península parou o seu movimento de rotação, desce agora a prumo, em direção ao sul, entre a África e a América Central, [...] e a sua forma, inesperadamente para quem ainda tiver nos olhos e no mapa a antiga posição, parece gêmea dos dois continentes que a ladeiam, vemos Portugal e Galiza ao norte, [...]. (SARAMAGO, 1988, p. 310).

Portugal e Espanha 'estão no mesmo barco' porque, historicamente, suas trajetórias se assemelham, ou seja, este - ainda que em menor escala - como aquele carrega o peso de uma situação determinada e consolidada por séculos de inferioridade e dependência cultural, sócioeconômica e política em relação à Europa. Portugal vê-se como uma sociedade semiperiférica - que "vive às margens do mundo, por dentro, numa espécie de isolamento sublimado" (LOURENÇO, 1999, p. 10) ${ }^{4}$ - responsável pelas trocas culturais entre o centro (Europa) e a periferia (ex-colônias). Por isso, o deslocamento da península não só tenta resgatar a identidade perdida, mas também promove a separação definitiva dos ideais ibéricos dos ideais europeus e, conseqüentemente, a alforria de Portugal e Espanha do continente europeu.

Já no plano individual, a viagem representa o monólogo interior, a busca metafísica de cada ser. Essa busca, aliás, constitui-se numa das principais indagações da obra:

então o que eu pergunto, se não somos o extremo menor desta cadeia de movimentos dentro de
movimentos, o que eu gostaria de saber é o que é que se move dentro de nós e para onde vai,
não, não me refiro a lombrigas, micróbios e bactérias, esses vivos que habitam em nós, falo
doutra coisa, duma coisa que se mova e que talvez nos mova, como se movem e nos movem
constelação, galáxia, sistema solar, sol terra, mar, península, [...] (SARAMAGO, 1988, p. 256).

A imagem da peregrinação humana, estruturada no inconsciente coletivo, caracteriza a viagem que proporciona a descoberta ou a indagação do saber-se quem se é: a busca da identidade perdida ou ameaçada. Nessa perspectiva, os planos individual e coletivo (nacional) se sobrepõem, uma vez que a Península Ibérica se separa do continente europeu para resgatar sua identidade, histórica e cultural, perdida ou ameaçada pela adesão de Portugal e Espanha à CE. Esse resgate, com efeito, dentro da obra, se processa na medida em que Saramago revive a vocação dos povos ibéricos em se lançarem às águas, dispersando-se pelo mar afora.

Aparentemente, o resgate da identidade perdida, modulado pelo ritmo do mar, é promovido a partir do afastamento da Península Ibérica do continente europeu, pois as fronteiras agora, existentes somente entre Portugal e Espanha, estão diluídas. A exemplo da época dos Grandes Descobrimentos, o homem volta a ser livre como era no mar. Os trechos abaixo resgatam o afeto entre o homem e seu país (península) e aludem ao orgulho e à liberdade dos antigos povos ibéricos, reconhecidos e respeitados pela sua nacionalidade:

\footnotetext{
${ }^{4}$ LOURENÇO, Eduardo. Mitologia da saudade: seguindo de Portugal como destino. São Paulo: Companhia das Letras, 1999.
} 
O tempo é de férias, pode ir e voltar sem ter de pedir licença, agora nem o passaporte exigem na fronteira, mostra-se simplesmente o bilhete de identidade e é nossa a península. (SARAMAGO, 1988, p.47-48)

agora não viajamos de comboio, vamos mais devagar em cima duma jangada de pedra que navega no mar, sem prisões, a diferença só é a que existe entre o sólido e o líquido. (SARAMAGO, 1988, p.80)

No trecho destacado, nota-se que a relação afetiva entre o homem e sua terra natal é retomada. O homem ibérico volta a ter orgulho de mostrar em sua documentação a sua nacionalidade, agora voltando a ser motivo de patriotismo e nacionalismo como era na época gloriosa. A tentativa de revitalizar a história, a partir do 'retorno' ao seu apogeu, começa a se delinear por meio do reconhecimento da nacionalidade. Tal proposta é, sobretudo, fundamentada pelo referencial histórico, tão caro aos povos ibéricos (principalmente aos portugueses), que alude aos gloriosos feitos do século XVI:

também foi dessas terras do sul que partiram os homens a descobrir o outro mundo, e também eles, duros, ferozes, suando como cavalos, avançaram dentro de couraças de ferro, na cabeça elmos de ferro, espadas de ferro na mão, contra a nudez dos índios, só vestidos de penas de aves e aguarelas (sic), idílica imagem. (SARAMAGO, 1988, p.80).

Resgatando o passado histórico, a partir de uma construção ficcional, a Península Ibérica, então, representa, alegoricamente, o papel das naus que, outrora trouxeram o esplendor do império aos países ibéricos, e o desmembramento da Península Ibérica do continente europeu simboliza o (re)começo da vida para os povos ibéricos. Sendo assim, a península "não viaja em direção ao passado, apenas traz o passado para o presente" ${ }^{\text {" }}$. Deve-se, é claro, relativizar essa reflexão, sabendo-se que nenhuma linguagem é utilizada de maneira inocente e, por isso, esse ressurgimento pleno do passado não poderá ser realizado, pois há lacunas, vazios e silêncios que não se recuperam mais. O que Saramago pretende, portanto, é (re)visitar o passado e deixar claro que seu discurso alegórico não se prende ao real, mas o (res)significa, criando um "efeito de real" (BARTHES, 1988, p. 156) ${ }^{6}$. É sob essa perspectiva, portanto, que A Jangada de Pedra, via discurso ficcional, dialoga com a História, uma vez que tenta resgatar o passado - preservando a cultura, a tradição e, sobretudo, a História, entre outros elementos fundadores da identidade -, trazendo-o para a complexidade do presente, marcado pela globalização e pelo multiculturalismo: os grandes responsáveis pelas crises de identidade. Desse modo, é válida a premissa de que, no contexto atual, não se pode mais

\footnotetext{
${ }^{5}$ Essa reflexão foi proposta a partir da leitura de Mitologia da Saudade, de Eduardo Lourenço (Op. cit. p. 59). No capítulo intitulado "Romantismo, Camões e a saudade", Lourenço afirma que Camões é um duplo Almeida Garrett. Garrett, nessa perspectiva, segundo Lourenço, ao incorporar traços da lírica camoniana à sua obra, não viaja realmente em direção ao passado, antes traz o passado para o presente.

${ }^{6}$ BARTHES, Roland. “O discurso da história”. In: O rumor da língua. São Paulo: Brasiliense, 1988. p. $145-157$.
} 
pensar em identidades nacionais únicas, visto que são as fronteiras culturais e não mais as fronteiras geográficas que as estabelecem.

A fusão identitária entre os portugueses e os espanhóis ${ }^{7}$, via coesão cultural e histórica, no entanto, reitera a posição de inferioridade de Portugal em relação ao continente europeu e à Espanha por, pelo menos, dois motivos. Em primeiro lugar, no que se refere à Europa, Portugal - n'A Jangada de Pedra, na península, “está virado para ocidente, para os Estados Unidos, a Espanha voltada para oriente, para a Europa" (SARAMAGO, 1988, p. 285) - assume definitivamente a sua condição de país periférico, no cenário europeu, reforçando, ainda mais, a idéia de que Portugal não pertence à Europa. Em segundo lugar, a gravidez das personagens Joana Carda (de nacionalidade portuguesa) e Maria Guavaira (de nacionalidade espanhola) é um dado que aponta para a supremacia dos espanhóis sobre os portugueses, pois a paternidade dos filhos dessas personagens é passível de dúvida, uma vez que ambas as personagens, embora se relacionem respectivamente com José Anaiço e Joaquim Sassa, ambos portugueses, têm relações sexuais com Pedro Orce, espanhol. Os filhos, advindos desse intercurso sexual, simbolizam o recomeço da vida dos povos ibéricos, portanto, têm grande possibilidade de serem espanhóis, revelando a superioridade dos espanhóis sobre os portugueses. Tanto o primeiro quanto o segundo aspecto reforçam o caráter de não-lugar de Portugal em relação ao continente europeu, seja pela posição geográfica (diametralmente oposta à Europa) em que esse país se localiza na Península Ibérica, seja pela superioridade étnica da 'nova' nação em que a nacionalidade espanhola se sobrepõe à portuguesa, gerada a partir da dúvida acerca da paternidade dos filhos de Joana Carda e Maria Guavaira: "as duas mulheres chamaram os seus homens de parte [...] lhes disseram, Estou grávida, e não sei se é de ti, se é de Pedro Orce" (SARAMAGO, 1988, p. 291).

\section{Portugal não se cumpriu: a dessacralização do mito}

O mito das glórias portuguesas é revivido, ainda que (res)significado n'A Jangada de Pedra. Nessa obra, Portugal se volta para o passado na busca de sua identidade histórica e social. No presente, em face do desajuste de Portugal em relação ao continente europeu, esse país periférico rememora sua identidade mítica, cuja saudade de reviver os grandes feitos,

\footnotetext{
${ }^{7}$ Para Maria Tereza Salistre, em A Jangada de Pedra: a desestabilização da história e da ficção, a nação portuguesa, n'A Jangada de Pedra, precisa afirmar sua identidade, procurando um traço de união com a Ibérica, dentro e fora da península. Dentro, ao se unir com os espanhóis e tentar fundar um novo continente; fora ao se lançarem no mar, buscando reviver o esplendor remoto.
} 
traduz-se numa viajem de retorno ao império histórico; num regresso alegórico ao passado mítico, portanto.

De acordo com Campbell (1990), em O Poder do Mito, os mitos são manifestações da alma humana, em cuja esfera os "sonhos arquétipos" (CAMPBELL, 1990, p. 4-16) do homem emergem a fim de alimentar a vida humana, edificando civilizações, instituindo valores, fundando crenças e dogmas, com o intuito de desvelar os mistérios mais recônditos da humanidade, oferecendo "modelos de vida" (CAMPBELL, 1990, p. 4-16) e mostrando tipos de reações que se deve ter diante de certas "crises de decepção, maravilhamento, fracasso ou sucesso" (CAMPBELL, 1990, p. 4-16).

Para Lourenço (1999), em Mitologia da Saudade: seguindo de Portugal como Destino, "a sacralização das origens faz parte da história dos povos como mitologia. Mas deve ser raro que algum povo tenha tomado tão à letra como Portugal essa inscrição, não apenas mítica, mas filial e já messiânica do seu destino [...]" (LOURENÇO, 1999, p. 91-2).

O dado trazido por Lourenço relaciona-se diretamente com a imagem que os portugueses têm de si, ou seja, a identidade mítica. Os projetos, os sonhos, as lembranças de si mesmos inseridos naquele passado glorioso, que condicionou, condiciona e condicionará seus destinos, reforçam a imagem que os portugueses fazem de si: a de um povo escolhido por Deus. É nesse mundo onírico, segundo Eduardo Lourenço (1999), que os portugueses se sentem em casa, pois dentro dele não se sentem estrangeiros. Nele "o seu lugar não se situa apenas no mapa. E muito menos se circunscreve ao pequeno retângulo, deitado à beira do Atlântico, carregado de passado e vida singulares, que chamamos Portugal” (LOURENÇO, 1999, p.11).

Especificamente no caso de Portugal é impossível conceber sua identidade cultural sem esbarrar no mito. Sabe-se que o povo português nutre (desde os tempos primevos de sua existência) uma grande predisposição para o messianismo, julgando ser um povo eleito por Deus. Tal predisposição ao mito pode ser justificada, ao se observar atentamente a História de Portugal, cujo início está associado à Guerra Santa, deflagrada pelos cristãos com o objetivo de expulsar os árabes da Península Ibérica. Associado a isso, não se pode deixar de mencionar que Portugal foi o primeiro país europeu a se constituir num Estado absolutista e mercantilista, devido as suas descobertas no período áureo, isto é, na época das navegações, em que Portugal se dispersou pelo mundo, descobrindo-o e batizando-o, de Cabo Verde à Índia, do Estreito de Magalhães às Filipinas.

Portanto, n'A Jangada de Pedra é a decadência desse passado glorioso e mitológico período das grandes navegações, dos grandes descobrimentos - ameaçado pela integração de 
Portugal à Comunidade Européia com a iminente ameaça de 'apagar' a identidade lusa (devido ao fenômeno da globalização) que impulsiona Portugal a fazer sua viagem alegórica em sentido inverso. Nessa esteira, Teresa Cristina Cerdeira da Silva (1999), em seu ensaio intitulado "Mar português - reescrever Portugal no verso e no reverso da aventura", apresenta uma visão de que Portugal é um país que se constituiu numa "mitologia cultural de país de viagem" (SILVA, 1994, p.56).

Para essa autora, "Portugal foi e é um país em viagem: da terra para o mar, no verso (camoniano?) da aventura marinheira; do mar para a terra, hoje, no reverso antiépico da sua trajetória cultural" (SILVA, 1994, p.56).

O ideal de país em viagem da terra para o mar é a tônica d'Os Lusíadas, de Luiz Vaz de Camões. Esse clássico poema camoniano reflete a exaltação do homem português na sua conquista de novas terras, via mar, com vistas a ampliar suas atividades comerciais e expandir seus domínios. Lusíadas não foi composto apenas para servir de referência mítica à cultura portuguesa, mas à vida portuguesa. Para os portugueses, de acordo com Eduardo Lourenço (1999), "Camões não será apenas o maior de seus poetas [...], mas o seu herói nacional" (LOURENÇO, 1999, p.57), uma vez que somente "o destino coletivo e a história do imaginário português podem explicar a conversão do autor d'Os Lusíadas em símbolo de Portugal” (LOURENÇO, 1999, p.57).

Para Victor Jabouille (1993), em Do Mythos ao Mito, o mito ganha força nos momentos de crise. É justamente nesses momentos que surgem os processos de mitificação da identidade nacional. N'A jangada de pedra, inserção de Portugal na Comunidade Européia, é um momento de crise para os povos ibéricos, pois a nova identidade se encontra deslocada em face do processo de globalização da economia e da mundialização da cultura. $\mathrm{O}$ resgate da tradição, através da revivência do mito camoniano, dentro da narrativa de Saramago, se configura como uma espécie de resistência à imposição de uma identidade global.

Se Os Lusíadas testemunham um momento grandioso, singular, da existência portuguesa, a proposta ficcional d'A Jangada de Pedra promove a desconstrução desse paradigma. Camões, em seu poema épico, narra e exalta as glórias do povo português, transformando sua obra num mito cultural positivo. Saramago, em sua narrativa anti-épica, narra o périplo e a estagnação da Península Ibérica no meio do Oceano Atlântico. Quando a península pára, fica ancorada no lugar de sua identidade histórica e cultural, ou seja, num ponto do oceano que sugere uma localização entre o Brasil e a África - antigas colônias portuguesas. Ao contrário do que ocorre com os heróis do poema épico de Camões, os antiheróis da narrativa anti-épica de Saramago se lançam ao mar - como os heróis camonianos - 
mas não descobrem nada, ficam estagnados no meio de dois povos, reforçando a condição semiperiférica de Portugal em relação à Europa. À luz do contexto histórico, Portugal, em face às demais nações do globo e em face a si mesmo, é um país estagnado e decadente. Essa parada simbólica, metaforicamente, representa que, mais uma vez, Portugal se defronta com uma indefinição de sua identidade, ameaçada pela globalização e pela mundialização culturais.

Zilá Bernd (1992), em Literatura e Identidade Nacional, explicita que as literaturas direcionadas às questões nacionais podem atuar como "forças sacralizantes" (BERND, 1992, p.18), na medida em que recuperam e solidificam os mitos da nação que narram, ou como "forças dessacralizantes" (BERND, 1992, p.18), resgatando os mitos para desestabilizá-los, desmistificá-los (BERND, 1992, p.18). Para tal, é preciso destruir o velho e já caduco mundo e construir um (re)começo absoluto, um mundo novo. Segundo as idéias Mircea Eliade (1972), em Mito e Realidade, a criação de um novo mundo só é possível graças à destruição dos vestígios e das ruínas do mundo antigo.

N'A Jangada de Pedra, pode-se constatar que não ocorre uma total destruição dos vestígios do mundo antigo. Há sim um grande deslocamento físico (o vagar da Península Ibérica pelo mar) e outro cultural, gerado diante da evidente falta de sintonia entre Portugal e o continente europeu. Evidentemente, a presença dos acontecimentos insólitos e a recuperação do mito do descobridor é o modo pelo qual José Saramago leva seus leitores a (re)pensar sobre as velhas e sérias questões peninsulares - as fronteiras geográficas e culturais - através do desprendimento ficcional (alegórico) da Península Ibérica que, no plano do redimensionamento histórico, representa a ruptura de Portugal com o continente europeu diante do cenário europeu. Por isso, como afirma Eunice Terezinha Gai (1992), no ensaio intitulado "A Jangada de Pedra: um redimensionamento mítico e histórico da civilização oriental”, "para redimensionar a história, é preciso passar pela recuperação mítica buscando nas origens a verdade sobre o ser" (GAI, 1992, p.230).

Saramago, assim, ao conceber a proposta ficcional d'A Jangada de Pedra, recupera o mito do descobridor português, mas, ao longo da narrativa, desestabiliza-o para, no desfecho, dessacralizá-lo. O mito de um povo escolhido por Deus se dilui, e o destino de Portugal, então, não se cumpriu, como nos versos de "O infante", de Fernando Pessoa: "Cumpriu-se o Mar, e o Império se desfez./ Senhor, falta cumprir-se Portugal!",

\footnotetext{
${ }^{8}$ CASSAL, Sueli Tomazini (Org.). Poesias - Fernando Pessoa. Porto Alegre: L\&PM, 1996.
} 


\section{Referências}

BARTHES, Roland. O discurso da história. In: O rumor da língua. São Paulo: Brasiliense, 1988.

BERND, Zilá. Literatura e identidade nacional. Porto Alegre: Editora da UFRGS, 1992.

CASSAL, Sueli Tomazini (Org.). Poesias- Fernando Pessoa. Porto Alegre: L\&PM, 1996.

CAMPBELL, Joseph. "O mito e o mundo moderno". In: . O poder do mito. São Paulo: Palas Athena, 1990.

ELIADE, Mircea. Mito e realidade. São Paulo: Perspectiva, 1972.

GAI, Eunice Terezinha Piazza. A jangada de pedra: um redimensionamento mítico e histórico da civilização oriental. In: Encontro de Professores Universitários Brasileiros de Literatura Portuguesa (14: 1992: Porto Alegre). Atas. Porto Alegre: Edipucrs, 1994.

JABOUILLE, Victor. "Uma mitologia portuguesa". In: Do mythos ao mito. Lisboa: Cosmos, 1993.

LOURENÇO, Eduardo. Mitologia da saudade: seguindo de Portugal como destino. São Paulo: Companhia das Letras, 1999.

. Nós e a Europa ou as duas razões. 4ed. Lisboa: Imprensa Nacional/Casa da Moeda, 1994.

. O labirinto da saudade: psicanálise mítica do destino português. 5.ed. Lisboa: Dom Quixote, 1992.

MEDINA, Cremilda Araújo. Viagem à literatura portuguesa contemporânea. Rio de Janeiro: Nórdica, 1983.

SARAMAGO, José. A jangada de pedra. São Paulo: Companhia das Letras, 1988.

SELISTRE, Maria Tereza. "A jangada de pedra: a desestabilização da história e da ficção". In: Encontro de Professores Universitários Brasileiros de Literatura Portuguesa (14: 1992: Porto Alegre). Atas. Porto Alegre: Edipucrs, 1994.

SILVA, Teresa Cristina Cerdeira da. "Mar português - reescrever Portugal no verso e no reverso da aventura". In: Estudos portugueses e africanos. Campinas, n. 24, jul./dez. 1994. 